\title{
The influence of phytoplankton composition on the relative effectiveness of grinding and sonification for chlorophyll extraction ${ }^{1}$
}

\author{
W. Y. B. Chang \& R. Rossmann \\ Great Lakes Research Division, The University of Michigan, Ann Arbor, MI 48109, U.S.A.
}

Keywords: grinding, sonification, chlorophyll, discriminant analysis

\begin{abstract}
The chlorophyll recovery efficiency was compared between control, ground, and sonified samples. The results showed significant improvement between control and ground samples but not between control and sonified samples. Neither prolonging time of sonification nor using an ice bath during filter grinding improved efficiency. Higher chlorophyll $a$ recovery was obtained from ground samples than from sonified ones, when the water samples contained centric diatoms and filamentous blue-green algae. When total phytoplankton numbers were high, there was a distinct advantage in using grinding rather than sonification for chlorophyll $c$ recovery.
\end{abstract}

\section{Introduction}

Complete pigment extraction is important to ensure accurate quantitative determination of the amounts of different chlorophyll pigments present in phytoplankton, but it is often unattainable because different groups of phytoplankton respond differently to extraction techniques. For certain species, mechanical cell destruction is necessary to obtain complete extraction. In such cases, grinding or sonification are often used to improve extraction (Tolstoy 1977).

Nelson (1960) and Laessøe and Hansen (1961) recommended sonification $(\sim 1 \mathrm{MHz}(1000 \mathrm{kc}))$ for complete pigment extraction from some phytoplankton species and to reduce the time needed for pigment extraction from marine phytoplankton. Grinding filters containing phytoplankton also increases pigment recovery and reduces the time needed for extraction (Yentsch \& Menzel 1963;

\footnotetext{
1 Contribution no. 313 of the Great Lakes Research Division, University of Michigan.
}

Kerr \& Subba Rao 1966). The purpose of this study was to compare the effectiveness of these methods using phytoplankton samples collected from the nearshore region of Lake Michigan during 1976 and 1977.

\section{Methods}

The experiments were conducted on 23 September and 9 November 1976 and on 12 July, 9 August, and 13 September 1977, using a modified version of the Strickland \& Parsons (1972) chlorophyll analysis procedure. Samples were collected minimally in triplicates, with frequently five or more replicates from a depth of $5.5 \mathrm{~m}$ in the intake forebay of the Donald C. Cook Nuclear Plant using a diaphragm pump. Each liter water sample was filtered through a Whatman ${ }^{\circledR} \mathrm{GF} / \mathrm{C}$ glass fiber filter. After most of the sample passed into the filtering flask, $1 \mathrm{ml}$ of saturated $\mathrm{MgCO}_{3}$ was added $\left(1 \mathrm{~g} \mathrm{MgCO}_{3} \cdot 4 \mathrm{H}_{2} \mathrm{O}\right.$ per $100 \mathrm{ml}$ distilled water) to prevent the decomposition of chlorophyll to phaeophytin. The filters were then placed into centrifuge tubes containing

Hydrobiologia 88, 245-249 (1982). 0018-8158/82/0883-0245/\$01.00. (c) Dr W. Junk Publishers, The Hague. Printed in the Netherlands. 
$10 \mathrm{ml}$ of $90 \%$ acetone.

Samples for each date were either ground, sonified, or received no treatment for cell destruction (control). Sonified samples were treated at the $70 \%$ power setting of a Biosonik III ${ }^{\circledR}$ sonifier (73.5 $\mathrm{W} / \mathrm{cm}^{2}$ ) for either $45 \mathrm{~s}$ or $3 \mathrm{~min}$. The ground samples were processed in tissue grinding tubes with $1.5-2 \mathrm{ml}$ of $90 \%$ acetone. The filters were ground at approximately $100 \mathrm{rpm}$ for $3 \mathrm{~min}$. The grinding tube was held firmly against the rotating pestle, lowered briefly, and then raised back against the pestle approximately every $15 \mathrm{~s}$. Contents of the grinding tube were then poured into a centrifuge tube. The tissue grinder was rinsed 3 times with $90 \%$ acetone. The rinse was added to the centrifuge tube to adjust the final volume of $90 \%$ acetone to $10 \mathrm{ml}$.

For 9 November 1976 only, samples were divided into six groups: (1) control, (2) 45 s sonification in an ice bath, (3) $45 \mathrm{~s}$ in an ice bath plus vigorous shaking, (4) 3 min sonification in an ice bath, (5) 3 min grinding, and (6) 3 min grinding in an ice bath.

Each sample was placed in a dark refrigerator for at least $15 \mathrm{~h}$ before measurements were made. After extraction, samples were inverted three times and centrifuged for $4 \mathrm{~min}$ at $2000 \mathrm{rpm}$ to separate filter fibers from the extract. Absorbances of the extracts relative to $90 \%$ acetone were measured at 665,645 , 630 and $750 \mathrm{~nm}$ using a Beckman DU ${ }^{\circledR}$ spectrophotometer. Results $\left(\mathrm{mg} / \mathrm{m}^{3}\right)$ were calculated using the Strickland \& Parsons (1972) equations for chlorophyll $b$ and $c$ and the Lorenzen equation
(Strickland \& Parsons 1972) for chlorophyll $a$.

Using a diaphragm pump, duplicate phytoplankton samples were collected at the same times and location as the pigment samples. They were preserved with $6 \mathrm{ml}$ of Lugol's solution per liter of sample. These samples were enumerated on slides prepared by the Sanford et al. (1969) settle-freeze method. Two complete transects were enumerated on each slide, one horizontal and one vertical to offset any patchiness that could occur during settling. Phytoplankton abundance was expressed in cells per milliliter, except for blue-green filaments with cylindrical trichomes, which were expressed in filaments per milliliter. Phytoplankton were subdivided into the following groups: coccoid bluegreen, filamentous blue-green, coccoid green, filamentous green, flagellates, centric diatoms, pennate diatoms, desmids, and others (Table 1).

Discriminant analysis was used to evaluate the difference in chlorophyll recovery effectiveness between grinding and sonification. The objective of discriminant analysis is to weigh and to combine linearly discriminating variables such that the combination of the variables for each group produces the largest possible univariate F-ratio (Harris 1975). For this analysis, discriminant variables that measured characteristics on which the groups were expected to differ were selected, and each group was assigned a dummy value. A ' 0 ' was assigned to the cases where grinding produced no significant improvement over sonification and a 'l' to the cases

Table 1. Phytoplankton densities (cells $/ \mathrm{ml}$ ), sonified (sonif.) chlorophyll concentrations $\left(\mathrm{mg} / \mathrm{m}^{3}\right.$ ), and ground chlorophyll concentrations averaged for each day of collection ( $\bar{X} \pm S D[N])$, where $\bar{X}$ is the mean, SD is standard deviation, and $N$ is the number of samples collected each day. An asterisk (*) indicates where grinding showed significant $(P<0.05)$ improvement over sonification.

\begin{tabular}{|c|c|c|c|c|c|c|c|}
\hline \multirow[b]{2}{*}{ Coc. B.G. } & \multicolumn{2}{|c|}{23 September 76} & 9 November 76 & 12 July 77 & \multicolumn{2}{|l|}{9 August 77} & 13 September 77 \\
\hline & 157.5 & $119.8(8)$ & $306.3 \pm 271.5$ & $129.4 \pm 107.8(8)$ & $1468.3 \pm$ & $941.4(8)$ & 828.5 土 $324.6(8)$ \\
\hline Fil.B.G. & 39.5 & $43.9(8)$ & $2.3 \pm 2.7$ & $61.6 \pm 53.7(8)$ & $22.5 \pm$ & $24.6(8)$ & $18.3 \pm 32.1$ \\
\hline Coc.Grn. & 884.0 & $497.9(8)$ & $136.5 \pm 129.9(8)$ & 133.8 土 & $123.3 \pm$ & $65.3(8)$ & $45.8 \pm 23.4(8)$ \\
\hline Fil.Grn. & 21.0 & $23.0(8)$ & $10.1 \pm 22.7$ & $18.1 \pm 11.6(8)$ & $0.0 \pm$ & $0.0(8)$ & $3.5 \pm 3.8(8)$ \\
\hline Flagell & 438.4 & $291.3(8)$ & $486.9 \pm 138.3$ & $281.6 \pm 132.5(8)$ & $391.3 \pm$ & $108.2(8)$ & $277.0 \pm 214.6(8)$ \\
\hline Centrics & 1317.9 & $487.9(8)$ & $1106.3 \pm 290.1$ & $978.4 \pm 288.8(8)$ & $174.4 \pm$ & $47.5(8)$ & $182.8 \pm 46.2(8)$ \\
\hline Pennates & 2570.6 & $\pm 1312.5(8)$ & $853.1 \pm 429.3(8)$ & $493.4 \pm 179.7(8)$ & $63.0 \pm$ & $33.7(8)$ & $147.8 \pm 57.2(8)$ \\
\hline Demids & 0.0 & $\pm \quad 0.0(8)$ & $0.0 \pm 0.0$ & $2.4 \pm 2.6(8)$ & $2.6 \pm$ & $2.7(8)$ & $0.0 \pm 0.0(8)$ \\
\hline Other & 556.8 & $\pm \quad 181.1(8)$ & $74.5 \pm 49.5(8)$ & $186.1 \pm 87.2(8)$ & $180.8 \pm$ & $51.4(8)$ & $49.9 \pm 12.9(8)$ \\
\hline Total & 6004.3 & $\pm 2293.6(8)$ & $2973.6 \pm 773.8$ & $2282.9 \pm 658.6(8)$ & $2424.5 \pm$ & 1093.2 & $1551.9 \pm 457.3(8)$ \\
\hline sonif. $a$ & 6.05 & $\pm \quad 0.16(3)$ & $2.62 \pm \quad 0.15(6)$ & $1.87 \pm \quad 0.89(5)$ & $1.88 \pm$ & $0.14(5)$ & $2.63 \pm 0.18(4)$ \\
\hline ground $a$ & 7.34 & $0.27(3)^{*}$ & $0.10(5)^{*}$ & $2.23 \pm$ & $1.82 \pm$ & $0.11(4)$ & $2.66 \pm$ \\
\hline sonif. $c$ & 1.11 & $0.04(3)$ & $0.07(6)$ & $0.29 \pm$ & $0.02 \pm$ & $0.02(5)$ & $0.66 \pm$ \\
\hline ground $c$ & 1.80 & $0.09(3)^{*}$ & $0.10(5)^{*}$ & $0.43 \pm$ & $0.29 \cdot \pm$ & $0.11(4)^{*}$ & $0.56 \pm$ \\
\hline
\end{tabular}


where grinding showed significant improvement over sonification.

\section{Results}

Since the euglenophycean population was consistently low in samples from the nearshore region of Lake Michigan and since green algae were scarce during the time the experiments were conducted, chlorophyll $b$ concentrations were very low and frequently below detectable levels. Therefore, no significant differences in the recovery of chlorophyll $b$ could be discerned.

Significant increases $(P<0.05)$ in concentrations of chlorophylls $a$ and $c$ were found between controls and ground samples but not between controls and sonified samples using the paired t-comparison (Table 2). Neither prolonging sonification time nor the use of an ice bath during grinding produced any sign of improvement in phytoplankton pigment recovery efficiency (Table 2). The 1976 analyses showed that 22-40\% higher chlorophyll $a$ and 62-87\% higher chlorophyll $c$ recovery characterized samples which were ground compared to those which were sonified. However, the 1977 results showed no significant differences in chlorophylls $a$ and $c$ recoveries except for the samples of 9 August (Table 1). The 9 August 1977 analyses indicated that grinding was better than sonification for recovery of chlorophyll $c$. These different findings may be attributed the composition of the phytoplankton assemblage in the water.

\section{Discussion}

Chlorophylls $a, b$, and $c$ concentrations in water samples are used to estimate phytoplankton bio- mass and photosynthetic capacity (Nelson 1960; Tolstoy 1977). Ratios between various plant pigments serve as indications of the taxonomic composition or physiological state of the community (Tolstoy 1977). Pigment concentrations and types in a sample depend on the kind and amount of phytoplankton in the water. Chlorophyll $a$ is found in all phytoplankton and is the primary photosynthetic pigment for them; chlorophyll $b$ is associated only with green algae and Euglenophyceae; chlorophyll $c$ is found in diatoms, dinoflagellates, and cryptophycean algae (summarized in Wetzel 1975).

Marker (1972) indicated that there are considerable difficulties in extracting pigment, particularly from water samples containing members of the Cyanophyceae and Chlorophyceae, and showed that grinding Oscillatoria and Chlorella resulted in $57 \%$ and $60-95 \%$ higher values than no grinding, respectively. Subba Rao \& Platt (1969) reported that prolonging grinding has a significant effect in the recovery of chlorophyll $a$ for the diatom Phaeodactylum tricornutum. Tolstoy (1977) further suggested that a grinder should always be used for samples containing Cyanophyceae and Chlorophyceae.

While some studies focused on improvement in extraction efficiency due to the grinding process, our effort was to see which kind of phytoplankton might cause significant differences in extraction efficiency in Lake Michigan. Based on discriminant analysis, differences in recovery of chlorophylls $a$ and $c$ between grinding and sonification for Lake Michigan phytoplankton were statistically significant (Table 3). When the samples contained centric diatoms and filamentous blue-green algae, grinding had a significant advantage over sonification in the recovery of chlorophyll a (Table 3 ). When total phytoplankton numbers were high, there was a distinct advantage in recovering chlorophyll $c$ by

Table 2. The paired t-comparisons for chlorophylls $a$ and $c$. Chlorophyll means $\left(\mathrm{mg} / \mathrm{m}^{3}\right)$ connected by lines are not significantly different $(\mathrm{p}<0.05)$ using $\mathrm{t}$-comparisons.

\begin{tabular}{lllllll}
\hline & $\begin{array}{l}\text { Control } \\
\mathrm{n}=6\end{array}$ & $\begin{array}{l}\text { sonif. } \\
(45 \mathrm{~s}) \\
\mathrm{n}=6\end{array}$ & $\begin{array}{l}\text { sonif. } \\
(3 \mathrm{~min}) \\
\mathrm{n}=3\end{array}$ & $\begin{array}{l}\text { sonif. } \\
(45 \mathrm{~s}) \\
\mathrm{n}=2\end{array}$ & $\begin{array}{l}\text { Ground } \\
(3 \mathrm{~min}) \\
\mathrm{n}=5\end{array}$ & $\begin{array}{l}\text { Ground in } \\
\text { ice bath } \\
(3 \mathrm{~min}) \mathrm{n}=2\end{array}$ \\
\hline Chlorophyll $a$ & 2.88 & 2.62 & 3.07 & $\underline{3.45}$ & 3.69 & 3.71 \\
Chlorophyll $c$ & $\mathbf{0 . 4 9}$ & 0.48 & 0.46 & 0.59 & 0.90 & 0.92 \\
\hline
\end{tabular}


Table 3. The results of discriminant analysis where D-square measures the success with which the discriminating functions actually discriminate between the ground and sonified chlorophyll samples (based on the data set presented in Table 1). The best discriminating variables indicate which kinds of phytoplankton contribute most significantly to the discrimination between the grinding and sonification results. * Significant at $0.05 ;{ }^{* *}$ significant at 0.01 ; and ${ }^{* * *}$ significant at 0.001 .

\begin{tabular}{lllllll}
\hline $\begin{array}{l}\text { Chlorophyll } \\
\text { types }\end{array}$ & D-square & F-stat & Signif. & $\begin{array}{l}\text { Best discriminating } \\
\text { variables }\end{array}$ & F-stat & Signif. \\
\hline$a$ & 4.4 & 20.7 & $* * *$ & $\begin{array}{l}\text { Centric diatoms } \\
\text { Filamentous blue- } \\
\text { green } \\
\text { Total population } \\
\text { density }\end{array}$ & 33.3 & $* * *$ \\
c & 1.2 & 11.2 & $*$ & 11.2 & $* *$ \\
\hline
\end{tabular}

means of grinding rather than sonification. When the above mentioned kinds of phytoplankton were absent from Lake Michigan samples and the total phytoplankton numbers were low, the same efficiency in recovery of chlorophylls $a$ and $c$ should be expected by sonification, grinding or absence of cell destruction.

Results of our comparison of phytoplankton assemblages to chlorophyll concentrations can be influenced by the following processes, which may affect the chlorophyll content of phytoplankton prior to or during the extraction: (1) endogenous processes occurring within phytoplankton in response to a deteriorating environment for growth, (2) physicochemical processes occurring subsequent to cellular lysis and (3) biological processes resulting from phytoplankton interaction with other organisms such as grazing herbivores, bateria and viruses (Daley \& Brown 1973). Daley \& Brown (1973) showed that chlorophyll concentration declined continuously in senescing cultures which had ceased to grow as a result of nutrient limitation. This suggests that if a natural population is under severe nutrient limitation, mechanical destruction of the cells may not significantly improve the efficiency of chlorophyll recovery due to the low level of chlorophyll present in those cells. The same results may also be expected from chlorophyll determinations performed on freshwater phytoplankton subjected extensively to herbivore predation or to bacterial and viral infestation; in such cases, grinding may not contribute significantly to chlorophyll recovery. In addition, photochemical oxidation may also negatively influence the efficiency of chlorophyll recovery using grinding, since postlytic photochemical oxidation is one of the principal mechanisms in chlorophyll diagenesis (Daley 1973). The study of Daley \& Brown (1973) showed that when the lysed-cell samples was incubated with oxygen aeration and light, chlorophyll was found to be very quickly destroyed as a result of photooxidation, whereas no chlorophyll destruction occurred in the intact cells or in lysed cells which were stored in the darkness. The implication is that using a darkened environment to incubate samples during the post-lytic period after grinding can be critical in maintaining the efficiency of chlorophyll recovery.

Kerr \& Subba Rao (1966) reported that the mean value for chlorophyll $a$ was optimum at $30 \mathrm{~s}$ grinding time, decreasing as grinding time increased and as the logarithm of extraction time increased using cultures of Nitzschia closterium. However, since different types of phytoplankton may react differently, the response to the treatments may vary with the systems. Therefore, it is recommended that for maximum chlorophyll recovery, the optimum combination of grinding time and post-grinding incubation should be explored prior to chlorophyll determination.

Strickland \& Parsons (1972) suggested that if poor extraction is anticipated, a grinder should be used. However, Tolstoy (1977) argued that since the effectiveness of extraction depends on the kind of phytoplankton, and since phytoplankton composition is generally not known at the time of chlorophyll analysis, a grinder should always be used. Since grinding was equally or more effective than sonification or no treatment, it is the recommended method of sample preparation on the basis of both better efficiency in pigment recovery and lower equipment cost. 


\section{Acknowledgments}

Comments from Drs. J. C. Ayers, E. F. Stoermer and R. A. Moll of the Great Lakes Research Division, and J. T. Lehman of the Biological Science Division, The University of Michigan, are gratefully acknowledged. The manuscript benefited substantially from criticism made by $D$. E. Whitney. Support was provided by the Indiana \& Michigan Electric Company.

\section{References}

Daley, R. T., 1973. Experimental characterization of lacustrine chlorophyll diagenesis. II. Bacterial, viral and herbivore grazing effects. Arch. Hydrobiol. 72: 409-439.

Daley, R. T. \& Brown, S. R., 1973. Experimental characterization of lacustrine chlorophyll diagenesis. I. physiological and environment effects. Arch. Hydrobiol. 72: 277-304.

Harris, R. J., 1975. A Primer of Multivariate Statistics. Academic Press, New York, $332 \mathrm{p}$.

Laessee, A. \& Hansen, Vagn Kr., 1961. Ultrasonic and extraction of chlorophyll a from phytoplankton. Plankton Committee Report no. 143. Cons. int. Explor. Mer.
Marker, A. F. H., 1972. The use of acetone and methanol in the estimation of chlorophyll in the presence of phaeophytin. Freshwat. Biol. 2: 361-385.

Nelson, D. J., 1960. Improved chlorophyll extraction method. Science 132: 351.

Sanford, G. R., Sands, A. \& Goldman, C. R., 1969. A settlefreeze method for concentrating phytoplankton in quantitative studies. Limnol. Oceanogr. 14: 790-794.

Strickland, J. D. H. \& Parsons, T. R., 1972. A practical handbook of Sea Water Analysis. Pigment Analysis Bull. Fish. Res. Bd Can. 167: 185-206.

Subba Rao, D. V. \& Platt, T., 1969. Optimal extraction conditions of chlorophylls from cultures of five species of marine phytoplankton. J. Fish. Res. Bd Can. 26: 1625-1630.

Tolstoy, A., 1977. Chlorophyll a as a measure of phytoplankton biomass. Acta Univ. Upsal. 416, 30 p.

Kerr, J. D. \& Subba Rao, D. V., 1966. Extraction of chlorophyll a from Nitzschia closterium by grinding. Monograph on Oeanographic Methodology 1: 65-69. UNESCO, Paris.

Wetzel, R. G., 1975. Limnology. W. B. Saunders, Philadelphia, $742 \mathrm{p}$.

Yentsch, C. S. \& Menzel, D. W., 1963. A method of the determination of phytoplankton chlorophyll and phaeophytin by fluorescence. Deep Sea Res. 10: 221-231.

Received 16 March 1981. 